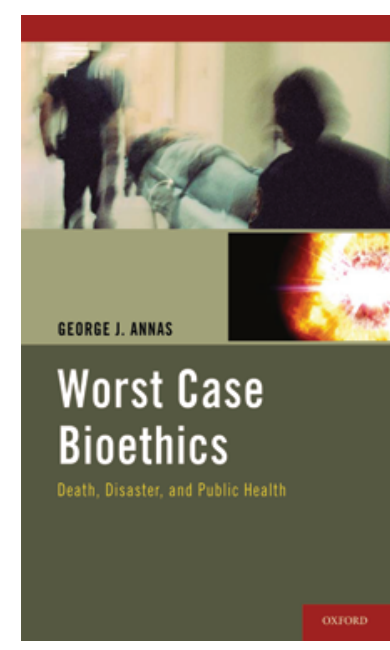

\section{Worst case bioethics}

\author{
Death, disaster, and public health
}

George J. Annas

Oxford University Press. New York, New York, USA. 2010.

360 pp. \$39.95. ISBN: 978-0-195-39173-2 (hardcover).

\section{Reviewed by Jeremy Sugarman}

Berman Institute of Bioethics and Department of Medicine, Johns Hopkins University, Baltimore, Maryland, USA.

E-mail: jsugarm1@jhmi.edu
W orst-case scenarios are commonplace in discussions and deliberations concerning science, new technologies, public health, and health care. Using worst-case scenarios can illustrate the potential hazards of some type of action (or inaction), which can be helpful in drawing attention to a set of particular concerns that may be of relevance. However, as well illustrated in George Annas' Worst Case Bioethics, worstcase scenarios can also shape policies and practices, sometimes to the detriment of individual interests.

Annas is chair of the Department of Health Care, Bioethics and Human Rights at the Boston University School of Public Health. He holds degrees in law and public health and is widely known for his work in health law, especially as it relates to public health, medicine, and bioethics. His work frequently privileges the perspectives of human rights and a robust defense of liberty interests. This book does the same.

Worst Case Bioethics takes on some of the most contentious issues that fall within the ambit of bioethics, broadly considered. The book comprises three parts. The first section, entitled "Death and Disaster," includes chapters covering American health care, bioterrorism and bioart, states of emergency, torture, hunger strikes, and war. This section highlights some challenging issues encountered in a post-9/11 world, such as the role of physicians who were involved with torture or hunger strikes. To say the least, these are not comfortable topics to discuss, and many may disagree with Annas's conclusions, but having a sense of the human rights concerns that are at issue in these sorts of situations is important.

The next section of the book, "Death and the Constitution," includes sections on cancer, drug dealing, "toxic tinkering," abortion, the "culture" of death, and patient safety. Here again, Annas addresses very topical and contentious issues, such as access to experimental medications, medical marijuana, clinicians' roles in executions, the popularized narrative of the death of Terry Schiavo, and patient safety. An underlying theme in this section is the relationship of state and federal laws regarding these issues, which helps to illuminate some of the political activity surrounding them.

In the final section, "Disaster and Public Health," Annas devotes discussion to global health, pandemic fear, and what he calls genetic genocide. These chapters cover a range of issues from recent public health concerns (such as pandemic flu) to work in the life sciences (such as DNA banking and cloning). Here, Annas provocatively contests other established approaches to these issues.
One strength of Worst Case Bioethics is its broad inclusion of contemporary topics, which not only provides relevant examples for different readers, but also underscores the need to consider seriously the implications of using worst-case scenarios in multiple domains. However, those interested in or working on particular issues are likely to be left wanting more - such as additional facts or perspectives, a serious review of alternate approaches and counterarguments, and a more complete explication of the arguments that lead to the conclusions that are announced.

Regardless, as Annas himself concludes Worst Case Bioethics, three basic rationales are frequently used in society to justify particular actions: "the action will save lives; promote national security and/or promote progress ... What they have in common is that they all embody an implicit worst case scenario: if we don't do ' $X$ ' (hundreds, thousands, or millions of) people will die, our country will be attacked, and/or we will remain ignorant (and reject all the good things more science and technology could bring to the human race)." Recognizing the presence and power of such worst-case scenarios may help us better understand the ethical implications of particular endeavors. In my mind, that would be a fine way to start thinking about bestcase bioethics. 